\title{
Memory and the Korsakoff syndrome: Not remembering what is remembered
}

\author{
Géry d'Ydewalle*, Ilse Van Damme \\ Department of Psychology, University of Leuven, B-3000 Leuven, Belgium \\ Received 31 March 2006; received in revised form 18 August 2006; accepted 25 August 2006 \\ Available online 26 September 2006
}

\begin{abstract}
Following the distinction between involuntary unconscious memory, involuntary conscious memory, and intentional retrieval, the focus of the present paper is whether there is an impairment of involuntary conscious memory among Korsakoff patients. At study, participants generated associations versus counted the number of letters with enclosed spaces or the number of vowels in the target words (semantic versus perceptual processing). In the Direct tests, stems were to be used to retrieve the targets with either guessing or no guessing allowed; in the Opposition tests, the stems were to be completed with the first word that came to mind but using another word if that first word was a target word; and in the Indirect tests, no reference was made to the target words from the study phase. In the Direct tests, the performance of Korsakoff patients was not necessarily worse than the one of healthy controls, provided guessing was allowed. More critical for the Korsakoff patients was the deficient involuntary conscious memory. The deficiency explained the suppression failures in the Opposition tests, the absence of performance differences between the Indirect and Opposition tests, the absence of a beneficial effect in providing information about the status of the stem, the performance boost when allowed to guess, and the very low rate of "Know"/"Remember" responses.
\end{abstract}

(C) 2006 Published by Elsevier Ltd.

Keywords: Korsakoff; Memory

Alcohol dependence for many years may lead to Korsakoff syndrome, if it is associated with nutritional thiamine deficiency (Butters, 1985; Homewood \& Bond, 1999). Due to lesions of the mammillary bodies, the dorsomedial thalamic nucleus (Kopelman, 1995; Victor, Adams, \& Collins, 1989), and the anterior thalamic nucleus (Harding, Halliday, Caine, \& Kril, 2000; Mayes, Meudell, Mann, \& Pickering, 1988; Warrington \& Weiskrantz, 1982), the Korsakoff syndrome is characterized by retro- and anterograde amnesia. Recent findings from brain imaging research (e.g., Emsley et al., 1996; Moselhy, Georgiou, \& Kahn, 2001; Reed et al., 2003) also suggest damage and/or activation atrophy particularly in the (pre)frontal lobes.

Performance on explicit tests of memory, such as free recall, is typically very poor (Kopelman, 1992). Explicit or direct memory tasks are those tasks in which the instructions at the time of test request retrieving a target event from the personal history. Implicit or indirect memory tests are tests requiring the par-

\footnotetext{
* Corresponding author.

E-mail address: gery.dydewalle@ psy.kuleuven.be (G. d'Ydewalle).
}

ticipant to engage in some cognitive or motor activity, where the instructions refer only to the task at hand, and do not make reference to prior events (Richardson-Klavehn \& Bjork, 1988). The facilitation on an implicit memory test by recently encountered information is called priming. Whether the implicit memory performance of Korsakoff patients is also impaired, is less certain.

More than 30 years ago, Warrington and Weiskrantz (1970) reported that amnesic patients could remember verbal material if tested in a situation that provided partial information about the target. The authors therefore suggested that the amnesic syndrome was not to be characterized as a failure of registration or consolidation, but rather as a retrieval deficit. Later, however, they retracted this "retrieval deficit" view (Warrington \& Weiskrantz, 1982). Moreover, evidence was obtained for strong similarities between normal memory after a long retention interval (or after inadequate study time) and immediate amnesic memory (Mayes \& Meudell, 1981a,b; Mayes, Meudell, \& Som, 1981; Meudell \& Mayes, 1984; Woods \& Piercy, 1974), leading to the conclusion that amnesics "retrieval deficits" are a consequence of poor memory rather than the cause. 
However, in agreement with the original ideas of Warrington and Weiskrantz (1970), McDowall (1981) showed that Korsakoff patients are capable of encoding to a semantic level, even without specific instructions to do so, but suffer from an inability to retrieve information without cues (e.g., in free recall). More recently, Carlesimo (1994) indeed observed no processing deterioration of amnesic (including Korsakoff) patients in three different types of implicit memory tests (free association, stem completion, and perceptual identification). Phaf, Geurts, and Eling (2000) applied a word-stem completion test in Korsakoff patients and healthy controls, and also failed to find a difference between the two groups. Contrary to Carlesimo (1994) although using the same procedure, the Korsakoff patients in Brunfaut and d'Ydewalle (1996) showed a performance deficit in one of the three implicit memory tests, namely the free association test which requires more conceptual, semantic processing.

One major problem of implicit memory tests is that they may be contaminated by the use of covert explicit memory strategies, which has already repeatedly been suggested (see, e.g., Barnhardt, 2004; Verfaellie, Gabrieli, Vaidya, Croce, \& Reminger, 1996). For example, in the word-stem completion test, when participants display a significant priming effect, it always remains possible that participants have understood that the stems can be completed with words presented during the study phase of the experiment, and have thus transformed a nominally implicit test into a functionally explicit one. The occasional occurrence of conscious awareness of past items may sometimes prompt participants to adopt an intentional retrieval strategy. However, since Korsakoff patients are impaired in explicit recollection, their performance on implicit tests is less likely to be affected by explicit contamination compared to controls. This may account for the occasional finding of an implicit memory deficit in Korsakoff patients. For example, Jenkins, Russo, and Parkin (1998) concluded that, as compared with amnesics, the presence of a larger levels-of-processing effect in their control group was unlikely to be due to better processing of the targets; it was more likely to be a by-product of an explicit memory contribution to a nominally implicit memory task.

To obtain a purer measure of implicit memory than the one provided by standard implicit memory tests, Jacoby (1991, 1998) and Richardson-Klavehn, Gardiner, and Java (1994) applied exclusion/opposition methodology to the word-stem completion task. The process-dissociation procedure of Jacoby $(1991,1998)$ was designed to distinguish between the processes of controlled and automatic retrieval. The contributions to performance made by the two processes were estimated from Inclusion and Exclusion tasks. For example, in the Inclusion version of a word-stem completion task, participants were instructed to use word stems (i.e., the first three letters of words) as cues to intentionally retrieve studied words but, if retrieval failed, to complete the stems with the first word that came to mind. In the Exclusion version of the word-stem completion task, participants were also instructed to use the stems as cues to retrieve studied words, but were subsequently supposed not to produce those words; instead, they had to complete the stems with the first other word that came to mind. Because conscious retrieval acts in opposing ways in the two tasks, subtracting the proportion of studied words produced in the Exclusion task from the proportion of studied words produced in the Inclusion task gave Jacoby $(1991,1998)$ an estimate of the controlled retrieval process. Studied words produced in the Exclusion task were attributed to the automatic retrieval process; automatic retrieval was then estimated by dividing the proportion of studied words produced in the Exclusion task by one minus the estimate for controlled retrieval.

Jacoby's framework identified memory awareness (A) with intentional retrieval and memory unawareness (U) with automatic or involuntary retrieval. Richardson-Klavehn et al. (1994), however, argued that it is necessary to make further independent distinctions based on retrieval intentionality (intentional versus involuntary) and awareness (conscious memory versus unconscious memory), and in particular, that it is necessary to take account of influences of memory that are involuntary, but accompanied by an awareness of the past (involuntary conscious memory).

As the present study followed the opposition methodology of Richardson-Klavehn et al. (1994), their experiment is described in more detail. In the study phase, participants either generated a semantic associate of the target word (Associate condition) or counted the letters with enclosed spaces in the target word (Enclosure condition). At test, participants were presented with three-letter stems corresponding to target words that either had or had not been presented earlier. One group of participants was instructed to use the stems in order to retrieve previously studied items (Direct test condition). A second group of participants was simply instructed to complete the stems with the first English word fitting the stem that came to mind (Indirect test condition). A third group of participants was instructed to complete the stems with the first word coming to mind, but to use another word if the first word coming to mind had been encountered previously in the experiment (Opposition test condition).

Participants in the Direct test, like those in the Indirect test, will sometimes produce items as a result of involuntary retrieval processes, while at the same time recognizing them as old items. By contrast, when items associated with conscious memory come to mind involuntarily in the Opposition test, those items will be excluded from participants' overt responses. Hence, Richardson-Klavehn et al. modified the process-dissociation analysis in order to take this involuntary conscious memory into account. In the modified analysis, next to intentional retrieval (IR), two forms of involuntary influences were explicitly distinguished: involuntary conscious memory (ICM) and involuntary unconscious memory (IUM). These involuntary influences are distinguished from intentional retrieval (IR). Intentional retrieval (IR) occurs when a participant uses a stem as a cue to retrieve a studied item; involuntary conscious memory (ICM) occurs when a participant gives the first word coming to mind, accompanied by the conscious awareness that it is a previously encountered item.

Thus, the novel predictions in Richardson-Klavehn et al. (1994) concerned the Opposition test condition. In this condition, participants could be expected to complete stems with previously encountered items only to the extent that they 
had no conscious memory for those items. As items processed semantically are typically well remembered and are associated with experiential judgments of conscious recollection (e.g., Gardiner, 1988), Opposition participants were therefore expected to be highly successful in excluding Associate items from their responses. As the Enclosure condition emphasizes graphemic information, but not semantic information, participants should be less successful in excluding these items. In comparison with the baseline rate of target production for new items, the production of items in the Associate condition was indeed low-an inhibition effect; on the other hand, items in the Enclosure condition showed a facilitation effect.

From numerous findings with explicit memory tests, it is generally agreed that Korsakoff patients face major problems with intentional retrieval (Kopelman, 1992). On the other hand, throughout the present paper the assumption is made that there is no involuntary unconscious memory (IUM) deficit among Korsakoff patients. Although no direct evidence against or in favor of such an assumption is available, a deficit is very unlikely considering their typically good performance level in implicit tests in the literature (and, as to be shown, in the Indirect test of the present Experiment 1). The critical question, and the research focus of the present paper, is whether there is a group difference in involuntary conscious memory (ICM). Is there an impairment of involuntary conscious memory among the Korsakoff patients? To answer the question, two comparisons in Experiment 1 are particularly important: performance of Korsakoff patients versus healthy controls in the Opposition test, and performance of Korsakoff patients in the Opposition versus Indirect tests.

First, a stem in the Opposition test will be erroneously completed with an old target word as a result of an involuntary unconscious influence of memory (IUM). If a word comes to mind as a result of an involuntary retrieval process which is associated with conscious memory (ICM), that item will be suppressed. If the Korsakoff patients show less suppression than the healthy controls, then the difference suggests less involuntary conscious memory (ICM) in the Korsakoff patients. Second, there will be a smaller difference in performance between the Opposition and Indirect tests with less involuntary conscious memory (ICM). If the Korsakoff patients are unable to consciously experience target words to be old ones, they will not suppress them in the Opposition test, completing the stems at the same level as in the Indirect test.

As in Richardson-Klavehn et al. (1994), Experiment 1 included a levels-of-processing manipulation. The levels-ofprocessing framework implies a benefit of semantic over perceptual processing in the word-stem completion test. Accordingly, the predicted performance difference in the two comparisons, as described in the preceding paragraph, was expected to be boosted following semantic processing, helping us to unravel the importance of involuntary conscious memory (ICM) in Korsakoff patients and in healthy controls. An alternative to the levels-of-processing framework is the transfer-appropriate processing view, which states that the level of performance on a task is positively related to the extent that cognitive operations at test are similar to those engaged in during initial learning (Morris, Bransford, \& Franks, 1977; Roediger, 1990; Roediger
\& Srinivas, 1993). However, as mentioned by Craik (2002), both approaches can be seen as complementary rather than antagonistic. When applied to a word-stem completion task (as the one used in the present study), the transfer-appropriate processing view states that the benefit in test performance of semantic over perceptual processed information is due to the fact that the semantic processing "matches" the retrieval task better. This however implies that there must have been semantic encoding. It does not necessarily mean that semantic encoding is deeper than perceptual encoding (as stated by the levels-of-processing framework), but it does state that there has been some kind of semantic encoding.

Semantic processing at encoding will thus improve performance in the Direct and Indirect tests, independently of whether the target words are remembered as old or not. In the Opposition test, semantic processing may enhance both involuntary unconscious and conscious memory (IUM and ICM), with more involuntary conscious memory (ICM), however, leading to more suppression. If Korsakoff patients have an involuntary conscious memory (ICM) deficit, only involuntary unconscious memory (IUM) will benefit from semantic processing, cancelling perhaps completely the suppression of target words.

\section{Experiments 1-4}

The four experiments in the present study involved each time a new group of Korsakoff patients and a new group of healthy controls. Average age, age range, and number of male and female participants in the two groups of each experiment are provided in Table 1. Korsakoff patients were residents from six chronic care facilities in Belgium. Only after extensive medical and psychiatric screening were the patients referred to these facilities, where emphasis lies more on care and attaining the highest level of independence possible than on medical treatment. All patients had a clinical diagnosis of alcoholic Korsakoff syndrome but demonstrated no decreased intelligence and no decreased visualspatial functioning. They all had histories of chronic alcoholism, were unable to recall day-to-day and current events (anterograde

Table 1

Average age, age range, and number of male and female korsakoff patients and healthy controls

\begin{tabular}{|c|c|c|c|c|}
\hline & Experiment 1 & Experiment 2 & Experiment 3 & Experiment 4 \\
\hline \multicolumn{5}{|c|}{ Average age (years) } \\
\hline $\begin{array}{c}\text { Korsakoff } \\
\text { patients }\end{array}$ & 53 & 53 & 50 & 54 \\
\hline $\begin{array}{l}\text { Healthy } \\
\text { controls }\end{array}$ & 54 & 51 & 47 & 51 \\
\hline \multicolumn{5}{|c|}{ Age range (years) } \\
\hline $\begin{array}{c}\text { Korsakoff } \\
\text { patients }\end{array}$ & $41-63$ & $39-72$ & $39-65$ & $36-63$ \\
\hline $\begin{array}{l}\text { Healthy } \\
\text { controls }\end{array}$ & $36-71$ & $45-58$ & $40-67$ & $40-72$ \\
\hline \multicolumn{5}{|l|}{ Male/female } \\
\hline $\begin{array}{c}\text { Korsakoff } \\
\text { patients }\end{array}$ & $23 / 1$ & $20 / 4$ & $12 / 3$ & $21 / 5$ \\
\hline $\begin{array}{l}\text { Healthy } \\
\text { controls }\end{array}$ & $14 / 12$ & $19 / 5$ & $11 / 4$ & $20 / 6$ \\
\hline
\end{tabular}


amnesia), were disoriented in time and place, and had retrograde amnesia. On the Auditory-Verbal Learning Test, scores were always in the severe memory deficit range. The patients showed a broad range of educational and vocational levels. They were given no medication that could affect memory. The availability of further neuropsychological assessment data varied greatly as a function of the psychiatric centers, making more detailed comparisons of the Korsakoff patients across the four experiments impossible.

In each experiment, the healthy and volunteering participants were selected from friends and family members, to match as closely as possible the age and the broad range of educational and vocational levels of the Korsakoff group. Among the healthy controls, there were no signs of any memory problems. All scores on the Auditory-Verbal Learning Test were in the nomemory deficit range.

Before starting a session, participants were informed about the general nature of the experiment, however without mentioning that memory would be important at test. At the end of a session, full description and explanation were provided. The experiments were approved by local ethics committees.

\section{Experiment 1}

\subsection{Methods}

\subsubsection{Materials}

The 60 target and 30 filler words were selected from Uit den Boogaart (1975); they all had a 20-60 frequency count in Dutch printed materials. The 60 target words were six-letter nouns. The three-letter stem corresponding to each target word was unique in the set of 60 , and could be completed in at least six different ways. The 30 fillers were adjectives and verbs; they ranged between 4 and 10 letters in length, but no 6-letter words were included. This was done to prevent Opposition participants from excluding encoded words by responding only with adjectives and verbs that were not six letters in length; they had to rely on memory for specific words to comply with the Opposition-test instructions.

Both target and filler words were randomly assigned to three pools (pools A, B, and C), each containing 20 target and 10 filler words. Each pool was then further subdivided into two 15-words subsets (A1 and A2, B1 and B2, and $\mathrm{C} 1$ and $\mathrm{C} 2$ ), each containing 10 target and five filler words. These 15 -words subsets formed the lists that were presented to the participants. The order of target and filler words within each list was random, except that the first and last words were always fillers, and there were no consecutive occurrences of fillers.

\subsubsection{Design}

At the study phase, encoding condition was manipulated within-subjects: The participants either generated a word related in meaning to a presented word (Associate condition), or counted the number of letters with enclosed spaces in a presented word (Enclosure condition). Each participant saw, randomly chosen, four of the six 15-words subsets. For half of the participants within each test condition, the first and third subsets were in the Associate condition and the second and fourth subsets were in the Enclosure condition; for the other half, the first and third subsets were in the Enclosure condition and the second and fourth subsets were in the Associate condition.

Test type was manipulated between-subjects: A stem-cued recall test (Direct condition), a standard stem completion test (Indirect condition), and a stem completion test with instructions to exclude words from the study phase (Opposition condition) were used. Following the procedure of Richardson-Klavehn et al. (1994), there were approximately twice as many participants in the Indirect (10 Korsakoff patients/10 healthy controls) and Opposition (9 Korsakoff patients/10 healthy controls) conditions than in the Direct condition (5 Korsakoff patients/6 healthy controls); within this restriction, further assignment of participants to testing conditions was random. The test for all three conditions consisted of three-letter stems corresponding to all targets (40 from the presented subsets and 20 new words from the two not-presented subsets).

All six possible combinations of word pools (A, B, and C) and encoding conditions (Associate, Enclosure, and not presented at the study phase) were used across participants. Combining the six-word/condition combinations with the two orders of encoding conditions resulted in 12 unique presentations. One of the 12 presentations was randomly selected for each participant.

The test list consisted of the stems for all target words, and was divided into 10 blocks of six items each. Each block contained two stems from each of the three word pools; words from a particular word pool could not occur consecutively on the list. The order of test words was the same for all participants.

\subsubsection{Equipment}

Stimuli were presented on a $12 \mathrm{in.} \mathrm{screen} \mathrm{of} \mathrm{a} \mathrm{laptop} \mathrm{computer;} \mathrm{their} \mathrm{pre-}$ sentation was programmed in MS-DOS. Words at the study phase and stems at the test were shown in uppercase white letters $(7 \times 12$ standard letter type $)$ on a black background. Words at the study phase were presented in the middle of the screen. Presentation was at a 3-s rate, with a interstimulus interval of $1 \mathrm{~s}$. Stems at the test phase were shown in three columns on a single window screen; participants in all conditions were instructed to work through the items from top to bottom and from left to right. After each stem completion, the experimenter saved the response in the computer.

\subsubsection{Procedure}

Participants were tested individually. Prior to the study phase, they were told that the experimenter was interested in their responses to some words which would be shown on a screen. If the experimenter asked them to generate an association, they were to say loudly a word closely related in meaning to the word on the screen. They could say the first word coming to mind, as long as it was meaningfully related to the word they were shown. They were told that rhymes and visually similar words were not acceptable responses. When someone gave such a response, he/she was simply asked to generate another word more related to the meaning of the stimulus word. Because acoustic or visual intrusions were so rare, they were not recorded; there were also no indications that the two groups of participants differed in number of intrusions.

If the experimenter asked them to count enclosures, the participants were to look at the word on the screen carefully and determine which letters in the word contained enclosed spaces. An enclosed space was defined as a space completely surrounded by lines, as in the letters A, B, D, O, P, Q, and R. They were to count and report orally the total number of enclosed letters. Two words were shown as examples and participants were asked to generate an association for one and count the number of enclosed letters for the other If necessary, the instructions were repeated and/or clarified. The experimenter then presented the four 15-words lists. Prior to each list, the screen showed the word "Enclosure" or "Associate"; in addition, the experimenter instructed the participant which type of response to make for that list, depending on encoding condition.

After the presentation of the fourth list, participants were asked to generate and write down as many cities and large towns of Belgium as possible. They typically used $5 \mathrm{~min}$ to perform this distractor activity. Participants were then given instructions for the completion test. The instructions varied depending on test condition. Participants in the Direct condition were told to use the threeletter stems as cues to help them recall the words that had been presented on the screen in the first part of the session. They were informed that some of the stems in the test list would not correspond to words they had seen earlier; therefore, they should not guess, but give a word orally only if they believed that they had seen it on the screen. Participants in the Indirect condition were told that they should give the first word that came to mind as a completion to each stem. They were warned that more than one word might come to mind, but that they should nevertheless respond with the first one. They were encouraged to work through the stems as quickly as possible, so as not to reflect too much about the responses. Participants receiving the Opposition test were given the same instructions as those in the Indirect condition, but in addition they were told that if the first word coming to mind was one of the words seen earlier, they should give another word instead. 
Table 2

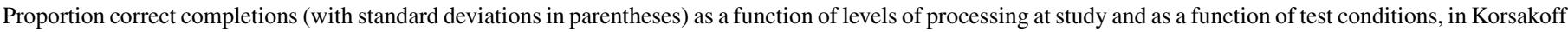
patients and healthy controls (Experiment 1)

\begin{tabular}{|c|c|c|c|c|c|c|}
\hline & \multicolumn{3}{|c|}{ Korsakoff patients } & \multicolumn{3}{|c|}{ Healthy controls } \\
\hline & New & Enclosure & Associate & New & Enclosure & Associate \\
\hline Indirect test & $.23(.12)$ & $.28(.14)$ & $.39(.15)$ & $.30(.07)$ & $.36(.10)$ & $.39(.11)$ \\
\hline Opposition test & $.25(.12)$ & $.41(.18)$ & $.46(.26)$ & $.27(.07)$ & $.25(.10)$ & $.18(.16)$ \\
\hline Direct test & $.06(.07)$ & $.14(.14)$ & $.22(.27)$ & $.04(.04)$ & $.12(.18)$ & $.38(.20)$ \\
\hline
\end{tabular}

\subsection{Results}

Table 2 gives the average proportion correctly completed old and new items from the complete design. An analysis of variance was carried out on the difference (i.e. priming) between the proportion correctly completed old and new items, as a function of Group (Korsakoff patients versus healthy controls) and Test (Indirect versus Direct versus Opposition) as between-subjects variables, and Encoding (Enclosure versus Associate) as within-subjects variable. Positive or facilitatory priming refers to more completion of old than new items; with inhibitory priming, there are less completions of old than new items. Although the term priming is commonly reserved for performance on Indirect tests, the same dependent variable (i.e., the difference between the proportion correctly completed old and new items) was used throughout the four experiments of the present study for the different types of test (Indirect, Direct, and Opposition tests); for the sake of clarity, the term priming will consistently be used to refer to the difference score.

Fig. 1 summarizes the most important (significant) findings of Experiment 1. With Korsakoff patients, there was more positive priming after Associate encoding than after Enclosure encoding, in the Indirect and Direct tests and old items in the Opposition test were not suppressed. In the Direct test, healthy controls showed more positive priming after Associate encoding than after Enclosure encoding; after Associate encoding, healthy controls showed significantly more positive priming than the Korsakoff patients.

There was a significant main effect of Encoding, $F(1,44)=8.212$, M.S.E. $=0.016, p<.01$, as well as a significant interaction between Group and Test, $F(2,44)=4.677$, M.S.E. $=0.045, p<.02$. Both significant effects were involved in a significant interaction between Group, Test, and Encoding,
$F(2,44)=3.411$, M.S.E. $=0.016, p<.05$. The averages from this interaction are depicted in Fig. 1.

With Korsakoff patients, a posteriori Tukey tests showed significantly more positive priming after Associate encoding than after Enclosure encoding, in the Indirect $(M=.16$ versus .05 , $p<.01)$ and Direct $(M=.16$ versus $.08, p<.05)$ tests, but not in the Opposition test $(M=.21$ versus .16, n.s.). In the Opposition test, Korsakoff patients showed a significantly larger difference between old and new items than the healthy controls, after Enclosure $(M=.16$ versus $-.02, p<.01)$ and Associate $(M=.21$ versus $-.09, p<.01)$ encoding. In the Direct test, healthy controls showed significantly more positive priming after Associate encoding than after Enclosure encoding $(M=.34$ versus .08 , $p<.01)$; after Associate encoding, healthy controls showed significantly more positive priming than the Korsakoff patients $(M=.34$ versus $.16, p<.05)$.

Planned comparisons within the Indirect conditions showed no significant priming among Korsakoff patients $(M=.05)$ and healthy controls $(M=.06)$ following a superficial Enclosure encoding; however, significant positive priming emerged after Associate encoding in both groups [among Korsakoffs, $F(1,18)=17.662$, M.S.E. $=0.007, p<.001 ; M=.16$, and among healthy controls, $F(1,18)=5.144$, M.S.E. $=0.007$, $p<.04 . M=.09$ ].

Following the Opposition instructions, no positive priming was to be expected: Old items, if remembered, should not be used to complete the stems. Fig. 1 suggests inhibitory priming among the healthy controls, particularly in the Associate condition, but the priming effects were not significant $(M=-.02$ and -.09 in the Enclosure and Associate conditions). The Korsakoff patients, on the other hand, showed significant positive priming after Associate encoding $(M=.21), F(1,17)=7.258$, M.S.E. $=0.016$, $p<.02$, and after Enclosure encoding $(M=.16), F(1,17)=6.394$, M.S.E. $=0.031, p<.03$.
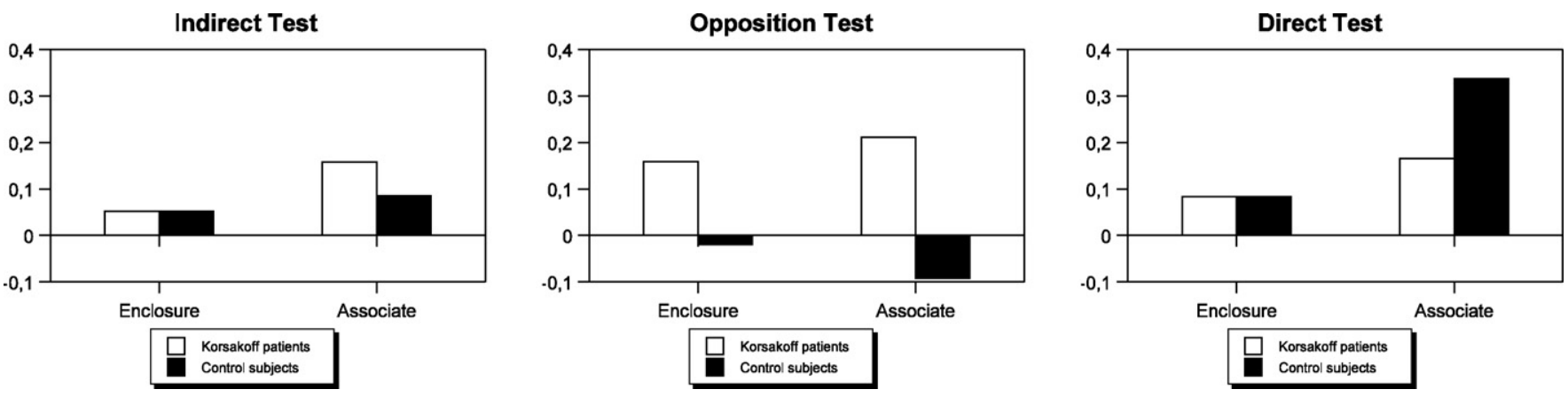

Fig. 1. Priming as a function of levels of processing at study and as a function of test conditions, in Korsakoff patients and healthy controls (Experiment 1). 
Planned comparisons within the Direct conditions showed no significant priming following Enclosure encoding, among Korsakoff patients $(M=.08)$ and among healthy controls $(M=.08)$; after Associate encoding, there was a significant positive priming among the healthy controls $(M=.34), F(1,9)=19.894$, M.S.E. $=0.017, p<.002$, and marginally significant positive priming among the Korsakoff patients $(M=.16), F(1,9)=3.962$, M.S.E. $=0.017, p<.08$.

\subsection{Discussion}

If Korsakoff patients show no or less involuntary conscious memory (ICM) than the healthy controls, then the Korsakoff patients were predicted to have problems in suppressing the old items in the Opposition test; also, their performance level in the Opposition test was to match their performance level in the Indirect test. The most striking result of Experiment 1 was the inability of the Korsakoff patients to suppress the old items in the Opposition test. In fact, they showed slightly more positive priming in the Opposition test than in the Direct test. From Fig. 1, it is also apparent that their performance level in the Opposition test matched their performance level in the Indirect test. Semantic processing at study was expected to enlarge the performance difference between Korsakoff patients and healthy controls. There was indeed a larger difference, with healthy controls showing significantly more priming in the Direct test and significantly more suppression in the Opposition test.

In the Indirect test, Korsakoff patients displayed significantly more (positive) priming after semantic processing than after perceptual processing; the same difference was however much smaller and not significant among the healthy controls. It has been widely believed that the level of processing does not influence priming in traditional incidental memory tests, including incidental word-stem completion tests, but the empirical evidence is quite inconsistent (as, e.g., reviewed by RichardsonKlavehn, Gardiner, \& Ramponi, 2002). When a levels-ofprocessing difference was obtained, it was often attributed to a contamination from occasional intentional retrieval. However, such an occasional intentional retrieval was more likely to occur among healthy controls, but here, it is surprisingly the Korsakoff patients showing the benefits from semantic processing. We have no obvious explanation to offer, except to state that the present data about the levels-of-processing effects in the Indirect test are in line with reported inconsistencies in the literature.

\section{Experiment 2}

Involuntary conscious memory (ICM) implies that a stem is completed and the completed stem is "recognized" as a target word (to be suppressed in the Opposition test and to be given in the Direct test). Accordingly, involuntary conscious memory (ICM) was expected to be improved when the experimenter provided information about the status of the stem (being part of either an old or new word). Such information was only to be beneficial when the completed stem was indeed the target word and when the target word was "recognized" as an old one. Experiment 2 attempted to improve performance by providing, in half of the conditions, cues: Each stem to be completed at test was preceded by a cue indicating whether the item was either an old or a new one (see also Richardson-Klavehn et al., 2002).

\subsection{Methods}

Experiment 2 used the same materials and procedure as Experiment 1, except for what follows. The Indirect condition was omitted, keeping only the Direct (12 Korsakoff patients/12 healthy controls) and Opposition (12 Korsakoff patients/12 healthy controls) conditions. In-between the study and test phases, there was no distractor activity (writing down city names) for half of the participants in each group and test condition. Also (orthogonally manipulated with the presence of the distractor activity) for half of the participants in each group and test condition, all stems were preceded by a cue informing the participants about the nature of the to-be-completed item ("New", "Old-Enclosure", or "Old-Associate"). Accordingly, the design included four between-subjects variables: Group (Korsakoff patients versus healthy controls), Test (Opposition versus Direct), Distractor activity (with versus without), and Cues (with versus without).

The Enclosure task of the study phase in Experiment 1 was perhaps too difficult for the Korsakoff patients and was replaced here for all participants by an easier vowel task: to count the number of vowels in the presented word. To get the participants (particularly the Korsakoff patients) more relaxed during the experiment, presentation of the words at the study phase was self-paced. After the appropriate word encoding, participants pushed the spacebar in order to proceed to the next word. As in Experiment 1, there were no time limits of the distractor activity for those receiving this interfering task; however, most participants stopped writing down the city names after about $5 \mathrm{~min}$. In the appropriate test conditions, the cues ("New", "Old-Vowel", or "Old-Associate") preceded each stem, with lowercase black $7 \times 12$ standard letters on a white background. A Superlab Pro program controlled the presentation of all items from the study and test phases.

\subsection{Results}

Table 3 gives the average proportion correctly completed old and new items from the complete design, except for the presence versus absence of the distractor activity.

An analysis of variance was carried out on the difference (i.e. priming) between the proportion correctly completed old and new items as a function of Group (Korsakoff patients versus healthy controls), Distractor activity (with versus without), Test (Direct versus Opposition) and Cue (with versus without) as between-subjects variables, and Encoding (Vowel count versus Associate) as within-subjects variable.

Before providing the details of the statistical analyses, we describe here the basic pattern of findings in Experiment 2 as it emerges from Figs. 2 and 3. The presence (versus absence) of a distractor activity did not affect the results; the main effect was not significant and its effect was not involved in any significant interactions. Cuing did not help the Korsakoff patients to have more positive priming in the Direct test or to show more inhibitory priming in the Opposition test; on the other hand, cuing did help the healthy controls, leading to more positive priming in the Direct test and more inhibitory priming in the Opposition test (as compared with the priming of the Korsakoff patients). In the Direct test, healthy controls showed more positive priming after semantic encoding than after perceptual encoding; the same difference was much smaller among Korsakoff patients. In the Opposition test, Korsakoff patients showed more positive priming after semantic encoding than 
Table 3

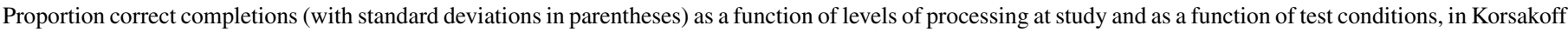
patients and healthy controls (Experiment 2)

\begin{tabular}{|c|c|c|c|c|c|c|}
\hline & \multicolumn{3}{|c|}{ Korsakoff patients } & \multicolumn{3}{|c|}{ Healthy controls } \\
\hline & New & Vowel count & Associate & New & Vowel count & Associate \\
\hline \multicolumn{7}{|l|}{ Direct test } \\
\hline Without cue & $.25(.13)$ & $.31(.11)$ & $.44(.15)$ & $.29(.10)$ & $.37(.12)$ & $.51(.20)$ \\
\hline With cue & $.16(.10)$ & $.28(.07)$ & $.29(.07)$ & $.28(.06)$ & $.46(.08)$ & $.66(.09)$ \\
\hline \multicolumn{7}{|l|}{ Opposition test } \\
\hline Without cue & $.28(.13)$ & $.32(.07)$ & $.42(.12)$ & $.15(.12)$ & $.21(.07)$ & $.08(.05)$ \\
\hline With cue & $.20(.10)$ & $.30(.07)$ & $.38(.09)$ & $.18(.13)$ & $.17(.09)$ & $.08(.07)$ \\
\hline
\end{tabular}
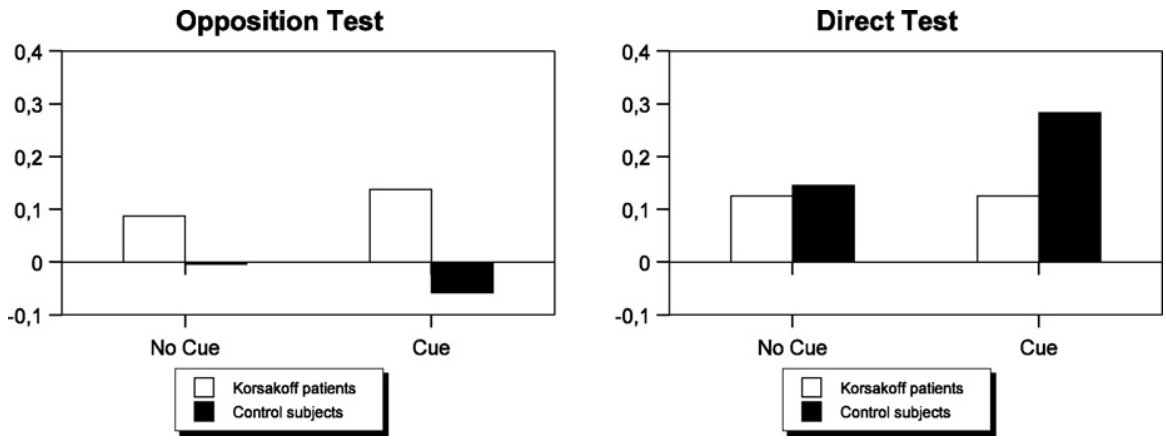

Fig. 2. Priming as a function of cues and test conditions, in Korsakoff patients and healthy controls (Experiment 2).

after perceptual encoding; on the other hand, healthy controls suppressed the target words more successfully after semantic encoding than after perceptual encoding.

There was a significant main effect of Test, $F(1,32)=22.156$, M.S.E. $=0.018, p<.0001$, and a significant interaction between Group and Test, $F(1,32)=18.075$, M.S.E. $=0.018, p<.0002$. However, they were both involved in two significant three-way interactions.

Fig. 2 describes the means involved in the first significant three-way interaction, $F(1,32)=4.847$, M.S.E. $=0.018, p<.04$, involving Group, Test, and Cue. Cues did not change significantly performance of the Korsakoff patients, neither in the Direct test ( $M=.13$ versus .13 , with versus without cues) nor in the Opposition test $(M=.14$ versus .09 , with versus without cues). Among the healthy controls, cues increased (positive) priming in the Direct test $(M=.28$ versus .15 , with versus without cues) and led to more inhibitory priming in the Opposition test $(M=-.06$ versus -.01 , with versus without cues), but both differences were not significant (Tukey test). However, the priming difference between Korsakoff patients and healthy controls was significant both in the Direct test with cues $(M=.13$ versus $.28 ; p<.02$, Tukey test $)$, and in the Opposition test with cues $(M=.14$ versus $-.06 ; p<.03$, Tukey test).

Planned comparisons within the Opposition test showed among Korsakoff patients significant positive priming with cues, $F(1,32)=12.553$, M.S.E. $=0.006, p<.002$, and with no cues, $F(1,32)=5.084$, M.S.E. $=0.006, p<.04$; the inhibitory priming effects of the healthy controls were not significant. In the Direct test, all priming effects were significantly positive: $F(1,32)=10.375$, M.S.E. $=0.006, p<.003$ with cues/Korsakoff patients; $F(1,32)=10.375$, M.S.E. $=0.006$, $p<.003$ without cues/Korsakoff patients; $F(1,32)=53.303$, M.S.E. $=0.006, p<.0001$ with cues/healthy controls; and $F(1,32)=14.121$, M.S.E. $=0.006, p<.001$ without cues/healthy controls.
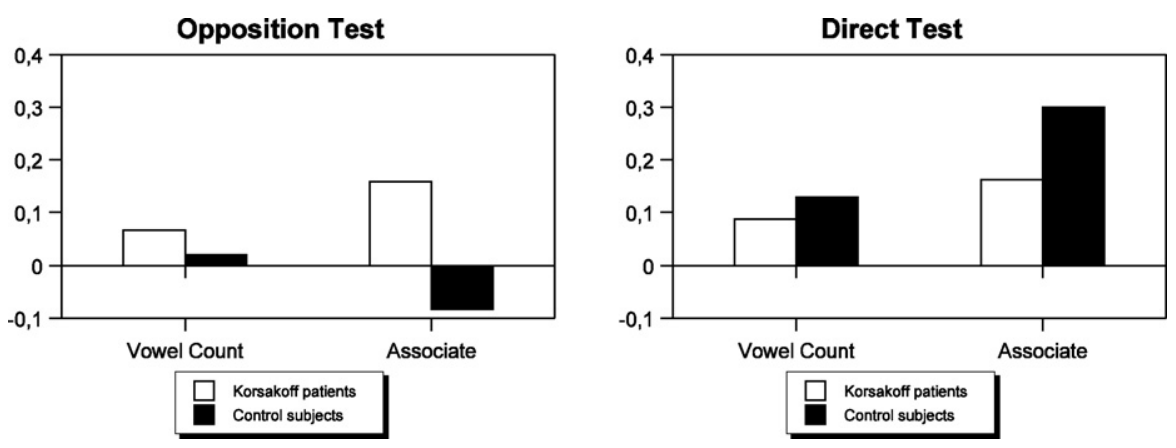

Fig. 3. Priming as a function of levels of processing at study and as a function of test conditions, in Korsakoff patients and healthy controls (Experiment 2). 
The means involved in the second significant three-way interaction, $F(1,32)=12.010$, M.S.E. $=0.011, p<.002$, involving Group, Test, and Encoding, are depicted in Fig. 3.

In the Direct test, healthy controls showed significantly more positive priming after semantic encoding than after perceptual encoding ( $M=.30$ versus .13, $p<.0003$, Tukey); the same difference was only marginally significant among Korsakoff patients ( $M=.16$ versus $.09 ; p<.08$, Tukey). With semantic encoding, healthy controls showed significantly more positive priming than Korsakoff patients ( $M=.30$ versus .16; $p<.01$, Tukey).

In the Opposition test, Korsakoff patients showed significantly more positive priming after semantic encoding than after perceptual encoding ( $M=.16$ versus $.07 ; p<.04$; Tukey); on the other hand, healthy controls suppressed more successfully after semantic encoding than after perceptual encoding $(M=-.08$ versus $.02 ; p<.02$, Tukey). With semantic encoding, the priming difference between healthy controls and Korsakoff patients was significant $(M=-.08$ versus $.16 ; p<.0001$, Tukey).

Planned comparisons within the Opposition test showed among Korsakoff patients and healthy controls no significant priming following Vowel Count encoding; after Associate encoding, Korsakoff patients showed significant positive priming, $F(1,32)=20.125$, M.S.E. $=0.007, p<.0001$, and healthy controls showed significant inhibitory priming $F(1,32)=5.575$, M.S.E. $=0.007, p<.02$. In the Direct test, all priming effects were significantly positive: $F(1,32)=6.681$, M.S.E. $=0.007$, $p<.02$ with Vowel Count encoding/Korsakoff patients; $F(1,32)=21.199$, M.S.E. $=0.007, p<.0001$ with Associate encoding $/$ Korsakoff patients; $F(1,32)=14.561$, M.S.E. $=0.007$, $p<.0006$ with Vowel Count encoding/healthy controls; and $F(1,32)=72.251$, M.S.E. $=0.007, p<.0001$ with Associate encoding/healthy controls.

\subsection{Discussion}

In half of the conditions of Experiment 2, cues provided information about whether the to-be-completed item was an old or a new one. The cues were expected to facilitate involuntary conscious memory (ICM), leading to more target words to be completed in the Direct test and particularly, more items to be suppressed in the Opposition test. However, with the cues, Korsakoff patients still failed to suppress the old items in the Opposition test and failed to complete more items in the Direct test. Facing the stem and the information that the stem was part of an old item, they were unable to realize that the target word which came to their mind was an old one. Accordingly, information about the status of the to-be-completed stem did not help to bypass the deficit in involuntary conscious memory (ICM). Healthy controls, on the other hand, were able to use the cues efficiently. With cues, they completed more target words in the Direct test and suppressed those items more frequently in the Opposition test, leading to a significant priming difference with the Korsakoff patients, both in the Direct and Opposition tests.

As in Experiment 1, semantic processing at study enlarged the performance difference between Korsakoff patients and healthy controls. Following semantic processing, there was indeed a larger difference (either with or without the cues), with healthy controls showing significantly more priming in the Direct test and significantly more suppression in the Opposition test than the Korsakoff patients.

\section{Experiment 3}

After semantic encoding in the Direct conditions of Experiments 1 and 2, healthy controls showed significantly more positive priming than Korsakoff patients. This does not necessarily reflect an encoding difference. Following the procedure of Richardson-Klavehn et al. (1994), the instructions for the Direct test in the present Experiments 1 and 2 asked the participants to use the stems as cues to retrieve items from the study phase but did not allow them to guess. As Korsakoff patients are assumed to have deficient involuntary conscious memory (ICM), they did not realize that the target word that popped out was an old one; therefore, they did not use it as a response. In Experiment 3 , there were two Direct conditions, one with guessing not allowed (as in Experiments 1 and 2, and in Richardson-Klavehn et al.) and the other where guessing was allowed. With guessing being allowed, the inability to realize that the target word that popped out is an old one, is of no importance, and the target word can be used to complete the stem. Therefore, the priming difference between Korsakoff patients and healthy controls was predicted to become smaller when guessing was allowed.

Following the test phase, Richardson-Klavehn et al. (1994) applied a modified version of the "Remember"/"Know" procedure in recognition research (for a review, see Gardiner, 2002). Participants were asked to indicate whether they remembered the item (i.e., recollect details of its occurrence at study) or whether they simply knew the item was there (i.e., have a sense of familiarity about the item without having a subjective experience of recollection). Gardiner (2002) followed Tulving (1972) in identifying the items receiving "Remember" responses as the only ones that had been retrieved episodically.

Experiment 3 included the "Remember"/"Know" procedure, which was introduced after the test phase in the Direct conditions. Pilot experimentation of Richardson-Klavehn et al. (1994) had revealed that recognition of items presented earlier was extremely rare among Opposition-test participants; it was therefore not considered worthwhile to instruct the Opposition-test participants of the present study to make "Remember" and "Know" judgments, due to the expected paucity of observations.

As Korsakoff patients in the Direct conditions are assumed to have a deficient involuntary conscious memory (ICM; i.e., being unable to realize that the target word which came to their mind was an old one), they will display a particularly low rate of "Remember" responses, and possibly also a low rate of "Know" responses.

\subsection{Methods}

Experiment 3 used the same materials and procedure as Experiment 1, except for what follows. At the test phase, stems were presented one by one in the center of the screen; after completing a stem, the participant pushed the space bar to obtain the next stem. A Superlab Pro program controlled the presentation of all items from the study and test phases, showing uppercase black standard letters on a white background. The Indirect condition was, as in Experiment 2, omitted. 
Next to the Opposition condition, there were two Direct conditions: Instructions either allowed or did not allow guessing. Both Korsakoff patients and healthy controls were randomly assigned to one of the three conditions. Accordingly, the design included two between-subjects variables: Group (Korsakoff patients versus healthy controls) and Test (Opposition versus Direct without Guessing versus Direct with Guessing).

After participants in the two Direct conditions had finished the completion test, the experimenter said loudly all 60 responses one by one, in the presentation order of the stems at the test phase. Participants were told that the experimenter was interested in their state of consciousness while they recalled the words, and that they were to place each word that they had recalled into one of two categories, "Remember" or "Know". The distinction between remembering and knowing that a word was encountered earlier was then explained to them in detail. They were to say "Remember" for a word if they consciously remembered the circumstances under which they encountered the word; they were to say "Know" for a word if they knew that it was seen previously, but did not recollect anything else about the word other than the fact that it was shown to them.

\subsection{Results}

The statistical analyses will highlight two salient findings. First, Korsakoff patients failed again to suppress the old items in the Opposition test; second, when allowed to guess in the Direct test, the Korsakoff patients were doing surprisingly well, showing a positive priming after semantic encoding which is even slightly larger than the positive priming among healthy controls; and finally, the "Know"/"Remember" response rate of the Korsakoff patients was almost non-existent (close to zero).

\subsubsection{Stem completion}

Table 4 gives the average proportion correctly completed old and new items as a function of Group (Korsakoff patients versus healthy controls), Test (Direct with guessing versus Direct without guessing versus Opposition), and Encoding (New versus
Enclosure versus Associate). An analysis of variance was carried out on the difference (i.e. priming) between the proportion correctly completed old and new items.

The main effects of Test and Encoding were significant, $F(1,24)=7.230$, M.S.E. $=0.020, p<.004$ and $F(1,24)=15.902$, M.S.E. $=0.013, p<.0006$. The interactions between Group and Test as well as between Group and Encoding were also significant, $F(1,24)=7.586$, M.S.E. $=0.020, p<.003$ and $F(1,24)=4.319$, M.S.E. $=0.013, p<.05$. They were all involved in a significant three-way interaction between Group, Test, and Encoding, $F(1,24)=4.328$, M.S.E. $=0.013, p<.03$; the means involved in the interaction are displayed in Fig. 4.

In the Direct test with guessing discouraged, healthy controls showed significantly more priming than the Korsakoff patients on Associate items $(M=.41$ versus $.03 ; p<.01$, Tukey), while there was no difference between the two groups on Enclosure items $(M=.06$ versus .05$)$. Healthy controls also showed significantly more priming on Associate items than on Enclosure items $(M=.41$ versus .06; $p<.01$, Tukey). Planned comparisons revealed only a significant priming of the healthy controls on Associate items, $F(1,24)=42.289$, M.S.E. $=0.010, p<.0001$.

A quite different picture emerged in the Direct test with guessing allowed. No difference appeared between the two groups; both groups (Korsakoffs and healthy controls) showed significantly more priming on Associate items $(M=.37$ and .32) than on Enclosure items $(M=.19$ and .15 ; both $p<.05$, Tukey). In the planned comparisons, all the priming effects were significant: Korsakoff patients on Enclosure items, $F(1,24)=13.412$, M.S.E. $=0.007, p<.002$, and Korsakoff patients on Associate items, $F(1,24)=34.440$, M.S.E. $=0.010$, $p<.0001$; healthy controls on Enclosure items, $F(1,24)=8.359$, M.S.E. $=0.007, p<.01$, and healthy controls on Associate items, $F(1,24)=25.761$, M.S.E. $=0.010, p<.0001$.

Table 4

Proportion correct completions (with standard deviations in parentheses) as a function of levels of processing at study and as a function of test conditions, in Korsakoff patients and healthy controls (Experiment 3)

\begin{tabular}{|c|c|c|c|c|c|c|}
\hline & \multicolumn{3}{|c|}{ Korsakoff patients } & \multicolumn{3}{|c|}{ Healthy controls } \\
\hline & New & Enclosure & Associate & New & Enclosure & Associate \\
\hline Opposition test & $.25(.08)$ & $.41(.08)$ & $.42(.05)$ & $.13(.08)$ & $.14(.13)$ & $.16(.14)$ \\
\hline Direct test (no guessing) & $.10(.05)$ & $.15(.17)$ & $.13(.16)$ & $.11(.06)$ & $.17(.07)$ & $.52(.23)$ \\
\hline Direct test (guessing) & $.18(.05)$ & $.37(.10)$ & $.55(.11)$ & $.23(.09)$ & $.38(.06)$ & $.55(.17)$ \\
\hline
\end{tabular}
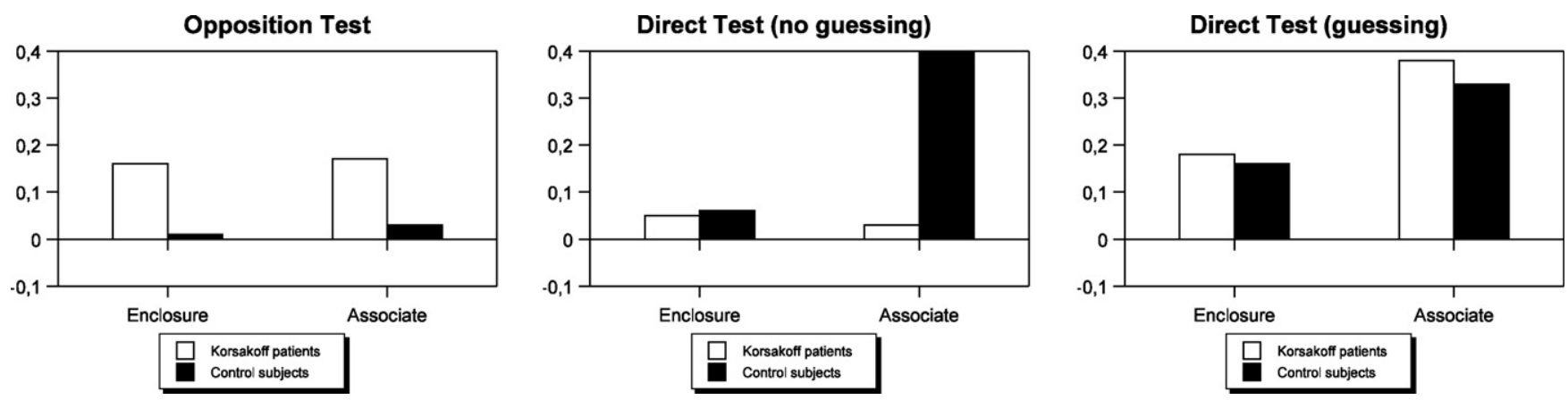

Fig. 4. Priming as a function of levels of processing at study and as a function of test conditions, in Korsakoff patients and healthy controls (Experiment 3 ). 
Table 5

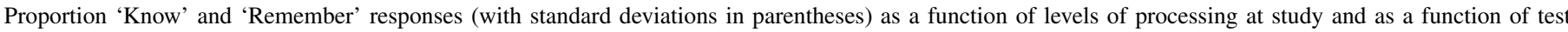
conditions, in Korsakoff patients and healthy controls (Experiment 3)

\begin{tabular}{|c|c|c|c|c|c|c|}
\hline & \multicolumn{3}{|c|}{ Korsakoff patients } & \multicolumn{3}{|c|}{ Healthy controls } \\
\hline & New & Enclosure & Associate & New & Enclosure & Associate \\
\hline \multicolumn{7}{|c|}{ Direct test (no guessing) } \\
\hline 'Know' & $.12(.16)$ & $.06(.05)$ & $.13(.12)$ & $.10(.05)$ & $.17(.04)$ & $.10(.06)$ \\
\hline 'Remember' & $.17(.23)$ & $.21(.29)$ & $.20(.29)$ & $.06(.07)$ & $.10(.06)$ & $.48(.24)$ \\
\hline \multicolumn{7}{|c|}{ Direct test (guessing) } \\
\hline 'Know' & $.04(.07)$ & $.06(.11)$ & $.07(.10)$ & $.34(.33)$ & $.32(.13)$ & $.20(.15)$ \\
\hline 'Remember' & $.39(.40)$ & $.36(.39)$ & $.35(.42)$ & $.24(.19)$ & $.35(.23)$ & $.57(.21)$ \\
\hline
\end{tabular}

In the Opposition test, Korsakoff patients again fail to suppress the old items with (marginally) significantly more priming on Enclosure and Associate items $(M=.16$ and .17$)$ than the healthy controls $(M=.01$ and .03 ; both $p<.06$, Tukey). Only Korsakoff patients show significant (positive) priming: Enclosure items, $F(1,24)=9.511$, M.S.E. $=0.007, p<.006$, and Associate items, $F(1,24)=7.270$, M.S.E. $=0.010, p<.02$ (planned comparisons).

\subsection{2. "Know"/"Remember" responses}

Table 5 gives the average proportion "Know" and "Remember" responses as a function of Group (Korsakoff patients versus healthy controls), Test (Direct with guessing versus Direct without guessing), and Encoding (New versus Enclosure versus Associate). Proportion of "Know" or "Remember" responses on new items were used as baseline and the analysis of variance was carried out on the proportion "Know" or "Remember" responses on old minus new items (i.e., priming).

Three main effects were significant: Group, $F(1,16)=17.449$, M.S.E. $=0.012, \quad p<.0008, \quad$ Encoding, $\quad F(1,16)=13.634$, M.S.E. $=0.005, p<.002$, and "Know"/"Remember" responses, $F(1,16)=5.855$, M.S.E. $=0.052, p<.03$. They were all involved in two significant higher-order interactions.

Direct conditions interacted significantly with Encoding, $F(1,16)=4.500$, M.S.E. $=0.005, p<.05$. There are more "Know"/"Remember" responses when guessing was not allowed than with guessing $(M=.12$ versus .04) on Enclosure items; the same difference disappeared on Associate items (both $M=.02)$.

More important is the significant interaction between Group, Encoding, and "Know"/"Remember" responses, $F(1,16)=$
21.179, M.S.E. $=0.012, p<.0003$. The means from the interaction are represented in Fig. 5. The interaction was exclusively due to a large number of "Remember" responses by the healthy controls on Associate items $(M=.38)$ which differed significantly from all other means ( $p<.0005$ at least; Tukey). No other differences were significant.

Planned comparisons within the means from Fig. 5 showed no priming among Korsakoff patients (all means at zero or close to zero) and no significant priming among healthy controls on all "Know" responses. On "Remember" responses, healthy controls showed significant priming on Enclosure items, $F(1,16)=8.257$, M.S.E. $=0.003, p<.02$, and on Associate items, $F(1,16)=47.771$, M.S.E. $=0.015, p<.0003$.

\subsection{Discussion}

Three sets of findings in Experiment 3 confirmed the involuntary conscious memory (ICM) deficit of the Korsakoff patients. First, when they were allowed to complete the stems by guessing (i.e., without taking into account the awareness to be an old item or not), their performance level was excellent and matched the level of the healthy controls. Second, and in agreement with Experiments 1 and 2, they failed again to suppress the old items in the Opposition test. Finally, a very low level of priming among Korsakoff patients on the "Know"//Remember" responses appears clearly from Fig. 5: In their verbal reporting, Korsakoff patients could not "remember" the old items and did not have a feeling of knowing.

When they were encouraged to guess, Korsakoff patients showed the same high level of priming after semantic encoding than the healthy controls on the same items. Nevertheless
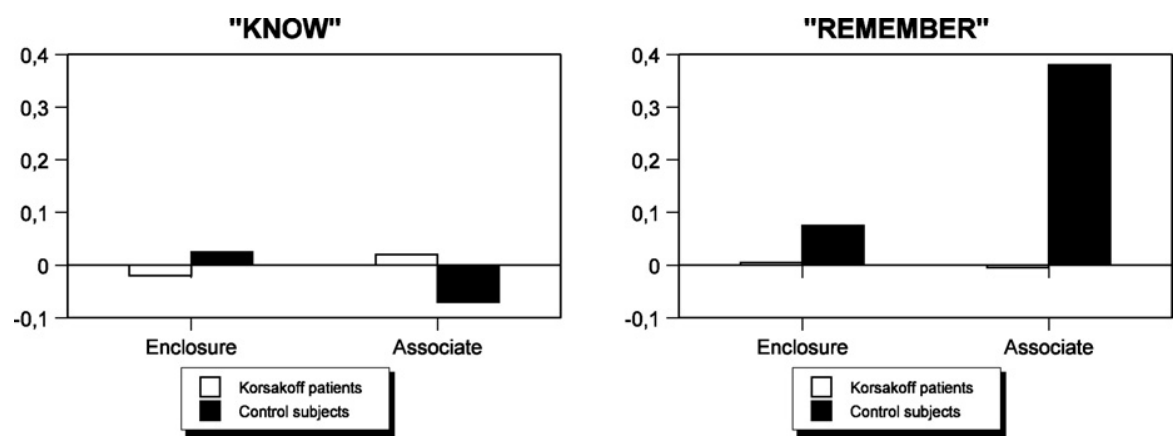

Fig. 5. Priming of 'Know' and 'Remember' responses as a function of levels of processing at study, in Korsakoff patients and healthy controls (Experiment 3). 
the Korsakoff patients were unable to "Remember" the items, while the healthy controls showed a high rate of "Remember" responses. Accordingly, the old items were available but the Korsakoff patients were unaware of the availability. Hence, priming for the Korsakoff patients reflected involuntary unconscious memory (IUM).

One may wonder whether there is a difference between direct tests with guessing as in the present experiment and indirect tests as in Experiment 1. In the instructions, the emphasis was different: either intentional retrieval or the first word coming to mind. Korsakoff patients are not expected to show a difference, considering their deficit in intentional retrieval; in fact, they did better in the Direct than in the Indirect conditions. For the healthy controls, the explicit retrieval should enhance their performance level in the Direct condition, particularly with associate (i.e., better encoded) items. The data confirmed this pattern.

\section{Experiment 4}

In Experiment 3, the "Know"/"Remember" responses were requested after finishing the test (completion) phase. The time interval may have diminished the item awareness from the first (encoding) phase. Experiment 4 included the "Know"/"Remember" procedure, but now the procedure was inserted during the test phase in a Direct condition. For each presented stem, participants were asked to complete the stem with a target word from the study phase and to indicate immediately afterwards whether they "Knew" or "Remembered" the item, leading to a more online reporting of their awareness.

\subsection{Methods}

Experiment 4 used the same materials and procedure as Experiment 1, except for what follows. In the study phase, the filler words were not included. The Indirect and Opposition conditions were omitted. Instructions for the Direct test phase allowed guessing when not remembering the item. A Superlab Pro program again controlled the presentation of all items, showing uppercase black standard letters on a white background. Test items were shown one by one, this time in a newly randomized order for each participant. Participants were told that the experimenter was interested in their state of consciousness when they completed a word. After each completion, they were asked if they were aware the item came from the study phase. If yes, they were to report loudly one of two categories, "Remember" or "Know". The distinction between remembering and knowing that a word was encountered earlier was explained to them in detail.

\subsection{Results}

The average proportion correctly completed old and new items, and the average proportion "Know" and "Remember" responses as a function of Group (Korsakoff patients versus healthy controls) and Encoding (New versus Enclosure versus Associate) are given in Table 6. In the stem completion, Korsakoff patients were doing surprisingly well: There was no priming difference between Korsakoff patients and healthy controls, with in both groups more priming after Associate encoding than after perceptual encoding. As in Experiment 3, the "Know"/"Remember" response rate of the Korsakoff patients was almost non-existent (close to zero).

\subsubsection{Stem completion}

An analysis of variance was carried out on the difference (i.e. priming) between the proportion correctly completed old and new items. There was only a significant main effect of Encoding, $F(1,50)=12.613$, M.S.E. $=0.015, p<.001$, with more priming after Associate encoding than after Enclosure encoding $(M=.23$ and .14). Importantly, Korsakoff patients did not show significantly less priming on Associate items than the healthy controls; the interaction between Group and Encoding was not significant.

Planned comparisons showed that all differences between old and new items were significant; that is, there was significant priming of Associate items for Korsakoff patients, $F(1,50)=34.693$, M.S.E. $=0.015, p<.001$, and for healthy controls, $F(1,50)=61.377$, M.S.E. $=0.015, p<.001$, but there was also significant priming of Enclosure items for Korsakoff patients, $F(1,50)=39.713$, M.S.E. $=0.007, p<.001$, and for healthy controls, $F(1,50)=33.838$, M.S.E. $=0.007, p<.001$.

\subsection{2. “Know"/"Remember" responses}

An analysis of variance was carried out on the proportion "Know" or "Remember" responses on old minus new items (i.e., priming). All main and interaction effects were significant. They were all due to the significant three-way interaction between Group, Encoding, and "Know"/"Remember" responses, $F(1,16)=11.259$, M.S.E. $=0.014, p<.002$. The means from the interaction are represented in Fig. 6. It is clear that the interaction was exclusively due to a large number of "Remember" responses by the healthy controls on Associate items $(M=.31)$ which differed significantly from all other means ( $p<.0005$ at least; Tukey). No other differences were significant.

Planned comparisons within the means from Fig. 6 showed no priming among Korsakoff patients (all means at zero or close to zero) and no significant priming of healthy controls for "Remember" responses on Enclosure items. On "Know" responses, healthy controls showed significant priming on Enclosure items, $F(1,50)=4.613$, M.S.E. $=0.006, p<.04$, and on Associate items,

Table 6

Proportion correct completions and 'Know' and 'Remember' responses (with standard deviations in parentheses) as a function of levels of processing at study, in Korsakoff patients and healthy controls (Experiment 4)

\begin{tabular}{lllllll}
\hline & \multicolumn{2}{l}{ Korsakoff patients } & & & \multicolumn{2}{l}{ Healthy controls } \\
\cline { 2 - 3 } \cline { 6 - 7 } & New & Enclosure & Associate & & New & Enclosure \\
\hline Completion & $.28(.13)$ & $.42(.13)$ & $.48(.16)$ & $.28(.12)$ & $.42(.12)$ & Associate \\
'Know' & $.03(.10)$ & $.05(.13)$ & $.08(.10)$ & $.09(.10)$ & $.14(.11)$ & $.18(.19)$ \\
'Remember' & $.07(.13)$ & $.07(.13)$ & $.12(.17)$ & $.03(.06)$ & $.05(.09)$ & $.34(.22)$ \\
\hline
\end{tabular}



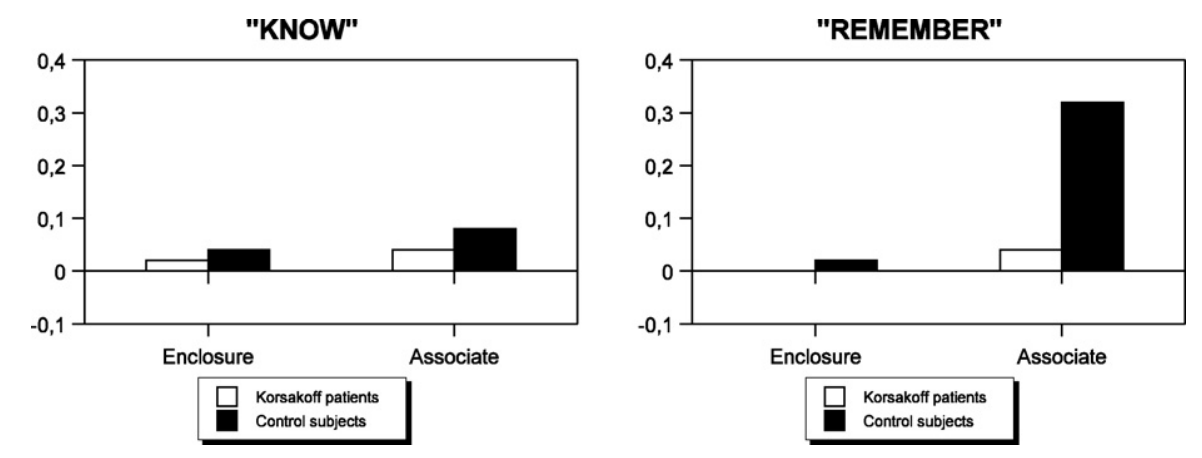

Fig. 6. Priming of 'Know' and 'Remember' responses as a function of levels of processing at study, in Korsakoff patients and healthy controls (Experiment 4).

$F(1,50)=13.134$, M.S.E. $=0.007, p<.001 ;$ they also showed significant priming for "Remember" responses on Associate items, $F(1,50)=70.527$, M.S.E. $=0.018, p<.0001$.

\subsection{Discussion}

Despite the procedural change to obtain a more direct reporting, the "Know"/"Remember" response rate of the Korsakoff patients remained very low in Experiment 4. Nevertheless, when allowed to guess (as in one of the two Direct conditions of Experiment 3), the Korsakoff patients again did not show significantly less word-stem priming on Associate items than the healthy controls.

\section{General discussion}

Despite claims that Korsakoff patients show poor intentional retrieval (see, e.g., Kopelman, 1992), the findings in the Direct tests from the present Experiments 3 and 4 show Korsakoff patients to perform at the level of the healthy controls, provided guessing is allowed. However, the good performance of the Korsakoff patients when they are allowed to guess suggests the importance of involuntary (unconscious?) memory, and not intentional retrieval, to produce the good performance.

More critical for the Korsakoff patients is the deficient involuntary conscious memory (ICM). The deficiency explains the suppression failures in the Opposition tests (Experiments 1-3), the absence of priming differences between the Indirect and Opposition tests (Experiment 1), the absence of a beneficial effect in providing information about the status of the stem (Experiment 2), the performance boost when allowed to guess (Experiments 3 and 4), and the very low rate of "Know"/"Remember" responses (Experiments 3 and 4).

\subsection{Inability to suppress old items}

Striking in the present first three experiments was the inability of the Korsakoff patients to suppress the old items in the Opposition condition. In the Opposition test of Experiments 1 and 3, Korsakoff patients displayed significant positive priming, either after perceptual or semantic encoding. In Experiment 2, there was significant positive priming only after semantic encoding. However, the general expectation was to get more suppression following semantic encoding than following perceptual encoding. In fact, the Korsakoff patients in Experiment 2 even showed significantly more positive priming after semantic encoding than after perceptual encoding, while there was no encoding difference in Experiments 1 and 3.

The inability of the Korsakoff patients to suppress the old items in the Opposition condition is not a new finding. In Experiment 1 of Cermak, Verfaellie, Sweeney, and Jacoby (1992), amnesics were told specifically not to utilize previously presented words during stem completion (Exclusion condition). This condition was contrasted with an Inclusion condition in which patients were encouraged simply to complete the stems with the first word that came to mind. Consistent with our findings, the amnesics' performance, unlike that of the alcoholic controls, did not significantly differ as a function of task condition. To examine whether amnesics' conscious recollection could be enhanced, their Experiment 2 presented the study list five times. The amnesics now were able to exclude a significant number of items from the study list; however, they still did so considerably less frequently than alcoholic controls.

New in the present experiments is the manipulation of the levels of processing at the study phase. According to both the levels-of-processing and the transfer-appropriate processing frameworks, semantic processing should facilitate the completion of the stems and should lead, in the Opposition test, to more suppression than perceptual processing. Clearly, our findings did not confirm this prediction with the Korsakoff patients. In fact, the Korsakoff patients in Experiment 2 showed significantly more positive priming after semantic encoding than after perceptual encoding, while there was no difference in Experiments 1 and 3.

The inability of the Korsakoff patients to suppress the old items in the Opposition tests, however, does not necessarily imply an encoding deficit. The old items were likely encoded and available at the test, but the Korsakoff patients did not experience them as old items. Accordingly, they did not inhibit them. A significant levels-of-processing effect (i.e. more priming after semantic encoding than after perceptual encoding) emerged in almost all Indirect, Direct, and Opposition tests with the Korsakoff patients, in the four experiments. Based on both the levels-of-processing and the transfer-appropriate processing frameworks, this implies that there must have been some kind of semantic encoding. The only exceptions were the Opposition 
test condition of Experiment 1 (see Fig. 1) and the Direct test condition of Experiment 3 where guessing was discouraged (see Fig. 4).

Two other findings are striking to note. First, in all Opposition tests, the facilitatory priming of the Korsakoff patients was stronger than the inhibitory priming of the healthy controls. Second, in the Direct test with guessing of Experiment 3 and in the Direct test (with guessing) of Experiment 4, the priming after semantic encoding of the Korsakoff patients was stronger (Experiment 3) than, or almost equal (Experiment 4) to the same priming of the healthy controls.

\subsection{Lack of experiencing conscious recollection?}

Several sets of data throughout the present four experiments suggest that the Korsakoff patients face a major problem at retrieval: the lack of experiencing conscious recollection at the test, despite the (involuntary) availability of the encoded items (ICM). Following semantic encoding, intentional retrieval (IR) in the Direct tests of Experiments 1-3 was significantly impaired (as compared with the same intentional retrieval of the healthy controls) when guessing was not allowed. Participants were instructed to use the stems as cues to retrieve items from the study phase. As Korsakoff patients were unable to recognize the (albeit available) old items and were discouraged to guess, many stems were left uncompleted leading to poor performance. Once guessing was allowed (Experiments 3 and 4), however, they did well: Old items, emerging involuntarily and unconsciously from memory, were used to complete the stems. This lack of experiencing conscious recollection at the test can also explain why Korsakoff patients were unable to inhibit old items in the Opposition tests (Experiments 1-3). Old items were not recognized to be old and were therefore used to complete the stems at the same level as the completion in the Direct no-guessing tests. Giving indications that the stem referred to a word from the study phase (the cues in Experiment 2) did not help as Korsakoff patients did not realize which word was coming from the study phase. Finally, the inability to experience conscious recollection produced of course a very low rate of "Know"/"Remember" responses (Experiments 3 and 4); this is in agreement with previous studies (Knowlton \& Squire, 1995; Schacter, Verfaellie, \& Anes, 1997) which showed amnesic patients to make fewer "Remember" and "Know" responses than controls.

According to an alternative explanation, the recollection deficit is due to a failure to encode contextual information. In McKone and French (2001), implicit memory of healthy subjects was not sensitive to study-test mismatch in environmental context while explicit memory was. This means that, in order to be fully able to explicitly recollect the encoded information, participants need to remember the spatiotemporal context. It is possible that what is missing in amnesia is the ability to encode the spatiotemporal context of the stimuli, while the retrieval process itself could be working normally. Poor conscious retrieval then arises because Korsakoff patients fail to encode the stimuli in the way that is necessary for conscious retrieval. It has indeed been reported repeatedly that Korsakoff patients have difficulties with remembering contextual information (e.g., Mayes, MacDonald,
Donlan, Pears, \& Meudell, 1992; Mayes, Meudell, \& Pickering, 1985). Similarly, Carroll (1987) and Johnson, Kim, and Risse (1985) have argued that the occasionally observed intact memory in amnesic patients results from the compatibility between passive, non-reflective, stimulus-driven test demands and the patients' relatively passive processing of the stimuli. Though the present study phase required some active processing, both the semantic and the perceptual tasks were relatively easy to do. It is indeed possible that the subsequent memory test in which guessing was allowed was more passive than the test in which guessing was not allowed, causing better compatibility with the easy study phase and therefore increased performance in the Korsakoff groups.

Thus, the retrieval problems of the Korsakoff patients are here explained in two different ways: lack of conscious recollection and failure to encode contextual information. According to the first explanation, the better performance of the Korsakoff patients when guessing is allowed follows from their inability to recognize items to be old ones; when guessing is not allowed, those items are not used to complete the stems. According to the second explanation, there is more compatibility between the patients' relatively passive processing of the stimuli at study and the passive, stimulus-driven test demands when guessing is allowed than when participants are explicitly discouraged to guess (which requires more contextual information).

The findings of the present study do not speak to the two possibilities. Although they do not exclude each other, we favor the first one. Using a procedure of Hay and Jacoby (1999), Van Damme and d'Ydewalle (2006) showed that Korsakoff patients were able to encode and recollect inter-item associations and contextual information to approximately the same level as controls. In an extension of Jacoby's $(1991,1998)$ original process-dissociation procedure, habits were created during an initial training session; memory performance was thereafter examined when habit opposed as well as worked in concert with recollection of a previous event in a cued recall test. The use of homographs and associations made it possible to examine semantic and contextual encoding and retrieval. The results showed that when given enough time and support, Korsakoff patients benefitted from the contextual, semantic information to the same extent as healthy controls did. The patients indeed showed problems with initiating and using active elaborative encoding on their own initiative, but when given more processing and response time, more explanation and explicit encouragement, their results improved up to the level of healthy participants. The results showed that Korsakoff patients not only are able to encode and make use of semantic information, but also to encode and remember both context and position in time, provided that they get enough time, explanation, and support.

\subsection{Failure to comply with the instructions?}

One could argue that the failure of the Korsakoff patients to suppress the old items in the Opposition tests was perhaps due to a failure to comply with the instructions because they did not keep them in mind. However, it is very doubtful that this was the case. Informal interviews at the end of the experiment made 
it abundantly clear that the instructions were well understood and remembered. Moreover, differences in the pattern of findings between test conditions provided indirect evidence that the Korsakoff patients were behaving differently as a function of the instructions. The priming effects of the Korsakoff patients were significantly stronger in the Opposition tests than in the Direct tests with guessing not being allowed (in Experiments 1 and 3 but not in Experiment 2). Moreover, the provided cues at each stem in Experiment 2 could be considered as instructional reminders; nevertheless, the reminders did not help. Particularly striking were the findings in the two Direct test conditions of Experiment 3: allowing or not to guess made an important difference, again suggesting indirectly that the Korsakoff patients were sensitive to the instructional difference.

\subsection{Dissociating and estimating retrieval components}

In the process-dissociation approach (Jacoby, 1991, 1998), aware and unaware retrieval components in the test performance (stem completion) can be calculated. The approach takes advantage of the fact that in the Inclusion task, aware (A) and unaware (U) processes both affect stem completion additively, while in the Exclusion task they work in opposition to each other. Specifically, successful completions in the Inclusion task reflect the contributions of both aware and unaware retrieval or, expressed mathematically, successful completions in the Direct test $=\mathrm{A}+\mathrm{U}(1-\mathrm{A})$. Conversely, in the Exclusion task, stems will be completed with a word from the study phase only if the word is retrieved unconsciously, without awareness $=\mathrm{U}(1-\mathrm{A})$. Using simple algebra, these simultaneous equations can be solved for $\mathrm{A}$ and $\mathrm{U}$, representing the proportion of stems in which the word from the study phase was retrieved with awareness or without awareness.

Details of test instructions are an important boundary condition for applying the process-dissociation methodology. The instructions used by Jacoby $(1991,1998)$ were meant to encourage participants to retrieve directly earlier-studied words, using word stems as cues (direct-retrieval strategy). For an Inclusion test, participants were instructed to use the stem as a cue to recall an old word and, only if they could not do so, to complete the stem with the first word that came to mind. For an Exclusion test, participants were instructed to use the stem as a cue to recall an old word, but subsequently not to use the recalled word to complete the stem. In Richardson-Klavehn et al. (1994), on the other hand, participants in the Opposition condition were instructed to complete the stems with the first word coming to mind, but to use another word if the first word coming to mind had been encountered previously in the experiment. According Jacoby (1998), such instructions lead to a generate-recognize strategy. Opposition on the basis of a generate-recognize strategy refers to cases in which an old word automatically comes to mind as a completion for a stem, without being consciously retrieved, but is then subjected to a voluntary, recognition-memory check and rejected because it is recognized as old. Participants' reliance on a generate-recognize strategy would violate one of the assumptions, the independence assumption, underlying the equations used by Jacoby $(1991,1998)$ to estimate A and U. A word must be generated before it can be recognized, and so conscious memory would not be independent of automatic influences of memory involved in generating a completion.

The process-dissociation approach of Jacoby $(1991,1998)$ and its formalization have been criticized on various grounds (see, e.g., Curran \& Hintzman, 1995; De Houwer, 1997; Esterman et al., 2002). According to the modified analysis of Richardson-Klavehn et al. (1994), a stem can be completed with a previously encountered target word in the Direct test condition because that word is intentionally retrieved (IR), or because that word is not intentionally retrieved, but is produced as a result of an involuntary retrieval process that is accompanied by an awareness of the past (involuntary conscious memory, or ICM) with a probability of [ICM(1 - IR)]. Finally, a stem can be completed with a target word owing to an involuntary unconscious influence of memory (IUM). This kind of unconscious influence will occur only when the word is neither intentionally retrieved, nor involuntarily retrieved and accompanied by an awareness of the past [IUM(1 - IR) $(1-$ ICM)]. The probability of completing a stem with an old target word in the Direct test condition can therefore be expressed as IR $+[\operatorname{ICM}(1-\mathrm{IR})]+[\operatorname{IUM}(1-\mathrm{IR})$ $(1-\mathrm{ICM})]$.

In the Opposition test, a stem can be completed with an old target word as a result of an involuntary unconscious influence of memory (IUM). However, for such an influence to occur, the subject must not intentionally retrieve the item $(1-\mathrm{IR})$. A word coming to mind as a result of an involuntary retrieval process must also fail to be associated with conscious memory ( 1 - ICM), otherwise that item will be omitted. In consequence, the probability of completing a stem with a target word in the Opposition test can be expressed as [IUM(1-IR) $(1-$ ICM $)]$.

The probability of responding with an old target word in the Indirect test can be written as $\operatorname{IR}+[\operatorname{ICM}(1-\mathrm{IR})]+$ $[\mathrm{IUM}(1-\mathrm{IR})(1-\mathrm{ICM})]$. According to this equation, stemcompletion responses in the Indirect test reflect involuntary influences of memory, both associated (ICM) and not associated (IUM) with conscious awareness of a past event. It also allows for the possibility that intentional retrieval (IR) could under some circumstances exert a facilitatory effect on indirect test performance, and is therefore identical, at least in form, to the equation for Direct test performance.

However, the assumption that intentional retrieval (IR) is the same in Direct, Indirect, and Opposition tests is most unlikely. Richardson-Klavehn et al. (1994) have argued that the likelihood that intentional retrieval is engaged in the Opposition test can be assumed to be close to zero, because it would not be a productive strategy in that task to use stems to retrieve studied words. Considering the task instructions (leading to a generaterecognition strategy) as used by Richardson-Klavehn et al. and in the present study, a more reasonable strategy would be to write down the first word coming to mind, and only to omit an item if it was associated with an awareness of prior occurrence. Finally, Richardson-Klavehn et al. have also argued that priming in the Indirect test condition does not reflect an appreciable influence of intentional retrieval. In other words, Richardson-Klavehn et al. are convinced about the noninvolvement of intentional retrieval in the Indirect and Opposition test conditions. 
Table 7

Estimates of involuntary conscious memory (ICM), involuntary unconscious memory (IUM), and intentional retrieval (IR) as a function of levels of processing at study, in Korsakoff patients and healthy controls (Experiment 1)

\begin{tabular}{|c|c|c|c|c|}
\hline & \multicolumn{2}{|c|}{ Korsakoff patients } & \multicolumn{2}{|c|}{ Healthy controls } \\
\hline & Perceptual & Associate & Perceptual & Associate \\
\hline $\begin{array}{l}\text { Involuntary conscious } \\
\quad(\mathrm{ICM})\end{array}$ & -.13 & -.07 & +.11 & +.21 \\
\hline $\begin{array}{l}\text { Involuntary unconscious } \\
\text { (IUM) }\end{array}$ & +.36 & +.43 & +.28 & +.23 \\
\hline Intentional retrieval (IR) & +.24 & +.27 & +.01 & +.22 \\
\hline
\end{tabular}

If IR in the Indirect and Opposition test conditions is at or close to zero $(1-$ IR) will be at or close to unity, simplifying the equations for performance in the Indirect and Opposition test conditions and allowing to estimate ICM and IUM from the data of those two conditions. We believe that the equation for the Direct test can also be simplified: As participants were requested not to guess (in Experiments 1 and 2, and in some conditions of Experiment 3), IUM in the Direct test will also be at or close to zero.

Performing the requisite calculations on the data of the present Experiment 1 yields estimates for ICM, IUM, and IR for the healthy controls and Korsakoff patients. From Table 7, it is immediately apparent that some of the estimates are meaningless: Some values are below zero, IR values of the Korsakoff patients are higher than the ones of the healthy controls, etc. Clearly, the model does not work. Part of the problem is due to more completion by the Korsakoff patients in the Opposition test than in the Direct test. Also, the present application of the modified process-dissociation analysis involves the assumption that intentional retrieval made a trivial contribution to performance in the Indirect and Opposition tests. Having to make such an assumption is not satisfactory, because the processdissociation and opposition procedures were designed to avoid having to make assumptions about the noninvolvement of intentional retrieval process in Indirect tests.

The present failed attempt to estimate the retrieval components in a process-dissociation paradigm is not an exception (for a review of failures and critiques, see e.g. Hirshman, 2004). Based on proven theorems, Hirshman (2004) presented an approach allowing to draw conclusions about the ordinal relations between retrieval components across conditions (without quantitative estimates of the components). Unfortunately, his approach requires an equal performance on new items across conditions and tasks. Such an equal performance of stem completion on new items (see Tables 2-4 and 6) was clearly not obtained in our four experiments. Differences in performance on new items across conditions and tasks likely reflected differences in guessing or response bias as a function of the instructions (either allowing to guess or not) and condition specificities. Accordingly, the approach of Hirshman could not be applied.

\section{Conclusion}

In summary, the present study demonstrates the lack of conscious recollection and how this inability affects memory retrieval of the Korsakoff patients. Using the procedure of Richardson-Klavehn et al. (1994), we showed that Korsakoff patients not only have problems with intentional retrieval, but also do not experience awareness when automatic retrieval confronts them with previously studied items (ICM). Close to one hundred years ago, in 1907, the Swiss psychologist E. Claparède already claimed that Korsakoff amnesia is attributable to a pathological process of dissociation that interferes with the ability to synthesize memories into the personal consciousness (see Nicolas, 1996).

While the present study highlights the retrieval problems of the Korsakoff patients, an encoding problem was not apparent in our findings. However, we cannot totally exclude encoding problems. For example, there is still the question as to whether a levels-of-processing manipulation elucidates all aspects of encoding. It leaves unanswered the question as to whether interitem associations and other contextual information is encoded in the study phase. One might argue that the recollection deficit is due to a failure to encode contextual information. Our findings do not speak to that possibility, and therefore do not fully rule out an encoding problem.

\section{Acknowledgements}

We are very much indebted to the following psychiatric centers in Belgium which were most helpful in coordinating the participation of their Korsakoff patients in the present study: Sint-Kamillus (Bierbeek), Sint-Amadeus (Mortsel), SintAmandus (Beernem), Bethanië (Zoersel), Sint-Nobertus (Duffel), and Ziekeren (Sint-Truiden). We are also grateful to Lien Dewanckel, Nienke Deblonde, Katrien Nelen, and Ann Santy for running Experiments 1-3. Ilse Van Damme is a research assistant from the Fund for Scientific Research Flanders. Thanks to Mieke Verfaellie for comments on a draft version of the present paper. We also thank Sachiko Kinoshita and Elinor McKone for their valuable suggestions to improve an earlier version of the manuscript. A summary of this work was presented at the January 2005 meeting of the Experimental Psychology Society, London, UK, and at the November 2005 meeting of the Psychonomic Society, Toronto, Canada.

\section{References}

Barnhardt, T. M. (2004). Different involuntary mechanisms underlie priming and LOP effects in stem completion tests. Memory, 12, 614-636.

Brunfaut, E., \& d'Ydewalle, G. (1996). A comparison of implicit memory tasks in Korsakoff and alcoholic patients. Neuropsychologia, 34, 1143-1150.

Butters, N. (1985). Alcoholic Korsakoff's Syndrome: Some unresolved issues concerning etiology, neuropathology, and cognitive deficits. Journal of Clinical and Experimental Neuropsychology, 7, 181-210.

Carlesimo, G. A. (1994). Perceptual and conceptual priming in amnesic and alcoholic patients. Neuropsychologia, 32, 903-921.

Carroll, M. (1987). Prior processing and picture naming in Korsakoff's syndrome. Australian Journal of Psychology, 39, 319-329.

Cermak, L. S., Verfaellie, M., Sweeney, M., \& Jacoby, L. L. (1992). Fluency versus conscious recollection in the word completion performance of amnesic patients. Brain and Cognition, 20, 367-377.

Craik, F. I. M. (2002). Levels of processing: Past, present ... and future? Memory, 10, 305-318. 
Curran, T., \& Hintzman, D. (1995). Violations of the independence assumptions in process dissociation. Journal of Experimental Psychology: Learning, Memory, and Cognition, 21, 531-547.

De Houwer, J. (1997). Differences in intentional retrieval during inclusion and exclusion tasks. Memory, 5, 379-400.

Emsley, R., Smith, R., Roberts, M., Kapnias, S., Pieters, H., \& Maritz, S. (1996). Magnetic resonance imaging in alcoholic Korsakoff's syndrome: Evidence for an association with alcoholic dementia. Alcohol and Alcoholism, 31, 479-486.

Esterman, M., McGlinchey-Berroth, R., Verfaellie, M., Grande, L., Kilduff, P., \& Milberg, W. (2002). Aware and unaware perception in hemispatial neglect: Evidence from a stem completion priming task. Cortex, 38, 233-246.

Gardiner, J. M. (1988). Functional aspects of recollective experience. Memory and Cognition, 16, 309-313.

Gardiner, J. M. (2002). Episodic memory and autonoetic consciousness: A first-person approach. In A. Baddeley, J. P. Aggleton, \& M. A. Conway (Eds.), Episodic memory: New directions in research (pp. 11-30). New York: Oxford University Press.

Harding, A., Halliday, G., Caine, D., \& Kril, J. (2000). Degeneration of anterior thalamic nuclei differentiates alcoholics with amnesia. Brain, 123, 141-154.

Hay, J. F., \& Jacoby, L. L. (1999). Separating habit and recollection in young and older adults: Effects of elaborative processing and distinctiveness. Psychology and Aging, 14, 122-134.

Hirshman, E. (2004). Ordinal process dissociation and the measurement of automatic and controlled processes. Psychological Review, 111, 553-560.

Homewood, J., \& Bond, N. W. (1999). Thiamin deficiency and Korsakoff's syndrome: Failure to find memory impairments following nonalcoholic Wernicke's encephalopathy. Alcohol, 19, 75-84.

Jacoby, L. L. (1991). A process dissociation framework: Separating automatic from intentional uses of memory. Journal of Memory and Language, 30, 513-541.

Jacoby, L. L. (1998). Invariance in automatic influences of memory: Toward a user's guide for the process-dissociation procedure. Journal of Experimental Psychology: Learning, Memory, and Cognition, 24, 3-26.

Jenkins, V., Russo, R., \& Parkin, A. J. (1998). Levels of processing and single word priming in amnesic and control subjects. Cortex, 34, 577588 .

Johnson, M. K., Kim, J. K., \& Risse, G. (1985). Do alcoholic Korsakoff's syndrome patients acquire affective reactions? Journal of Experimental Psychology: Learning, Memory, and Cognition, 11, 22-36.

Knowlton, B. J., \& Squire, L. R. (1995). Remembering and knowing: Two different expressions of declarative memory. Journal of Experimental Psychology: Learning, Memory, and Cognition, 21, 699-710.

Kopelman, M. D. (1992). The 'new' and the 'old': Components of the anterograde and retrograde memory loss in Korsakoff and Alzheimer patients. In L. R. Squire, \& N. Butters (Eds.), Neuropsychology of memory (pp. 130-146). New York: Guildford Press.

Kopelman, M. D. (1995). The Korsakoff syndrome. British Journal of Psychiatry, 166, 154-173.

Mayes, A. R., MacDonald, C., Donlan, L., Pears, J., \& Meudell, P. R. (1992). Amnesics have a disproportionately severe memory deficit for interactive context. Quarterly Journal of Experimental Psychology, 45A, 265297

Mayes, A. R., \& Meudell, P. R. (1981a). How similar is the effect of cueing in amnesics and in normal subjects following forgetting? Cortex, 17, 113-124.

Mayes, A. R., \& Meudell, P. R. (1981b). How similar is immediate memory in amnesic patients to delayed memory in normal subjects: A replication, extension and reassessment of the amnesic cueing effect. Neuropsychologia, 19, 647-654.

Mayes, A. R., Meudell, P. R., Mann, D., \& Pickering, A. (1988). Location of lesions in Korsakoff's syndrome: Neuropsychological and neuropathological data on two patients. Cortex, 24, 367-388.
Mayes, A. R., Meudell, P. R., \& Pickering, A. (1985). Is organic amnesia caused by a selective deficit in remembering contextual information? Cortex, 21, 167-202.

Mayes, A. R., Meudell, P. R., \& Som, S. (1981). Further similarities between amnesia and normal attenuated memory: Effects with paired-associate learning and contextual shifts. Neuropsychologia, 19, 655-664.

McDowall, J. (1981). Effects of encoding instructions on recall and recognition in Korsakoff patients. Neuropsychologia, 19, 43-48.

McKone, E., \& French, B. (2001). In what sense is implicit memory "episodic": The effect of reinstating environmental context. Psychonomic Bulletin and Review, 8, 806-811.

Meudell, P. R., \& Mayes, A. R. (1984). Patterns of confidence loss in the cued recall of normal people with attenuated recognition memory: Their relevance to a similar amnesic phenomenon. Neuropsychologia, 22, 41-54.

Morris, C. D., Bransford, J. D., \& Franks, J. J. (1977). Levels of processing versus transfer appropriate processing. Journal of Verbal Learning and Verbal Behavior, 16, 519-533.

Moselhy, H. F., Georgiou, G., \& Kahn, A. (2001). Frontal lobe changes in alcoholism: A review of the literature. Alcohol and Alcoholism, 36, 357-368.

Nicolas, S. (1996). Experiments on implicit memory in a Korsakoff patient by Claparède (1907). Cognitive Neuropsychology, 13, 1193-1199.

Phaf, R. H., Geurts, H., \& Eling, P. A. T. M. (2000). Word frequency and word stem completion in Korsakoff patients. Journal of Clinical and Experimental Neuropsychology, 22, 817-829.

Reed, L. J., Lasserson, D., Marsden, P., Stanhope, N., Stevens, T., Bello, F., et al. (2003). FDG-PET findings in the Wernicke-Korsakoff syndrome. Cortex, 39, 1027-1045.

Richardson-Klavehn, A., \& Bjork, R. A. (1988). Measures of memory. Annual Review of Psychology, 39, 475-543.

Richardson-Klavehn, A., Gardiner, J. M., \& Java, R. I. (1994). Involuntary conscious memory and the method of opposition. Memory, 2, 1-29.

Richardson-Klavehn, A., Gardiner, J. M., \& Ramponi, C. (2002). Levels of processing and the process-dissociation procedure: Elusiveness of null effects on estimates of automatic retrieval. Memory, 10, 349-364.

Roediger, H. L. (1990). Implicit memory: Retention without remembering. American Psychologist, 45, 1043-1056.

Roediger, H. L., \& Srinivas, K. (1993). Specificity of operations in perceptual priming. In P. Graf, \& M. E. J. Masson (Eds.), Implicit memory: New directions in cognition, development, and neuropsychology (pp. 17-48). Hillsdale, NJ: Erlbaum

Schacter, D. L., Verfaellie, M., \& Anes, M. D. (1997). Illusory memories in amnesic patients: Conceptual and perceptual false recognition. Neuropsychology, 11, 331-342.

Tulving, E. (1972). Episodic and semantic memory. In E. Tulving, \& W. Donaldson (Eds.), Organization of memory (pp. 381-403). New York: Academic Press.

Uit den Boogaart, P. C. (1975). Woordfrequenties in de geschreven en gesproken Nederlandse taal [Word frequencies in written en spoken Dutch]. Utrecht: Oosthoek, Scheltema en Holkema.

Van Damme, I., \& d'Ydewalle, G. (2006). Semantic processing in the Korsakoff syndrome: Context vs. habit. Submitted for publication.

Verfaellie, M., Gabrieli, J. D. E., Vaidya, C. J., Croce, P., \& Reminger, S. L. (1996). Implicit memory for pictures in amnesia: Role of etiology and priming task. Neuropsychology, 10, 517-528.

Victor, M., Adams, R. D., \& Collins, G. H. (1989). The Wernicke Korsakoff syndrome. Philadelphia, PA: F.A. Davis.

Warrington, E. K., \& Weiskrantz, L. (1970). Amnesia: Consolidation or retrieval? Nature, 228, 628-630.

Warrington, E. K., \& Weiskrantz, L. (1982). Amnesia: A disconnection syndrome? Neuropsychologia, 20, 233-248

Woods, R. T., \& Piercy, M. (1974). A similarity between amnesic memory and normal forgetting. Neuropsychologia, 12, 437-445. 